\title{
A EVASÃO EM CURSO DE PEDAGOGIA A DISTÂNCIA: UM OLHAR A PARTIR DOS TUTORES
}

\author{
DESERCIÓN EN EL CURSO DE PEDAGOGÍA A DISTANCIA: UNA MIRADA \\ DE LOS TUTORES
}

\section{EVASION IN A DISTANCE-EDUCACION PEDAGOGY COURSE: A GLIMPSE FROM THE TUTORS' PERSPECTIVE}

\author{
Gisele do Rocio CORDEIRO ${ }^{1}$ \\ Maria Lourdes GISI ${ }^{2}$
}

\begin{abstract}
RESUMO: Este trabalho tem como objeto de estudo a evasão na educação superior, uma problemática que decorre de múltiplas causas relacionadas tanto a fatores internos como externos às instituições de ensino. Além das dificuldades de acesso por parte dos jovens, observa-se, em dados do INEP (2016), uma diferença acentuada na relação entre ingressantes e concluintes, demonstrando significativa evasão. $\mathrm{O}$ estudo tem como principal referencial teórico-metodológico os escritos de Bourdieu (2000; 2003; 2010; 2014); Bourdieu e Passeron (2016) e foi realizado mediante análise de dados de estudantes a partir das justificativas apresentadas para a interrupção dos estudos de um curso de pedagogia a distância. Analisaram-se, também, dados dos professores/tutores do Curso mediante aplicação de questionário. A análise tomou como critério fatores relacionados às condições econômicas, ao curso e ao perfil dos alunos. A pesquisa evidencia os motivos da evasão e sua relação com diferentes fatores, com acentuada ênfase nas dificuldades de aprendizagem.
\end{abstract}

PALAVRAS-CHAVE: Educação superior. Acesso. Permanência. Evasão.

RESUMEN: Este trabajo tiene como objeto de estudio la deserción en la educación superior, una problemática que transcurre de múltiples causas relacionadas tanto a factores internos como externos a las instituciones de enseñanza. Además de las dificultades de acceso por parte de los jóvenes, se observa en datos del INEP (2016) una diferencia acentuada en la relación entre ingresantes y concluyentes, demostrando significativa deserción. Esta investigación tiene como principal referencial teórico metodológico las escrituras de Bordieu (2000; 2003; 2010, 2014); Bourdieu; Passeron (2016) y, el análisis se realizó de acuerdo con los datos de los estudiantes, a partir de las justificativas dadas para la interrupción de estudios de un curso de pedagogía a distancia. Además, se analizaron los datos de los profesores/tutores del curso mediante la aplicación de un cuestionario. El análisis tomó como criterio factores relacionados

\footnotetext{
${ }^{1}$ Centro Universitário Internacional (UNINTER), PR - Brasil. Doutoranda em Educação pela Pontifícia Universidade Católica do Paraná. ORCID: <http://orcid.org/0000-0001-5322-4145>. E-mail: gisele.c@uninter.com

${ }^{2}$ Pontifícia Universidade Católica do Paraná (PUCPR) - PR - Brasil. Professora titular da Pontifícia Universidade Católica do Paraná. ORCID: 〈https://orcid.org/0000-0002-0474-474X>. E-mail: maria.gisi@pucpr.br
} 
con las condiciones económicas, con el curso y con el perfil de los alumnos. La investigación evidencia los motivos de la deserción y su relación con diferentes valores, señalando, principalmente, las dificultades de aprendizaje.

PALABRAS CLAVE: Educación superior. Acceso. Permanencia. Deserción.

ABSTRACT: This research has, as object of study, the evasion in university education, a problem that is due to multiple causes related to factors, which may be intern and extern to the universities. Besides the difficulties in access from the young students, we have noticed in the data from INEP (2016) a striking difference in the relation to the beginners and the concluders, demonstrating significant evasion. The study has, as main theoretical-methodological reference, the writings by Bourdieu (2000; 2003; 2010; 2014); Bourdieu; Passeron (2016) and was carried out upon the students' data analyses which refer to the reasons presented to justify the interruption of the studies of a distance-education pedagogy course. The professors/tutors' data were also analyzed through the replies of a questionnaire. The analysis has taken as criterion the factors related to the economic conditions, the course and the students' profile. The research shows the reasons for evasion and its relation to the different factors, with greater emphasis on the learning difficulties.

KEYWORDS: University education. Access. Permanence. Evasion.

\section{Introdução}

Busca-se neste estudo investigar a evasão em curso de Pedagogia, um curso que tem como foco de estudos o campo teórico investigativo da educação, do ensino, das aprendizagens e do trabalho pedagógico presentes na prática profissional docente. Conforme consta nas DCNs para a formação do licenciado em Pedagogia, é central:

I - o conhecimento da escola como organização complexa que tem a função de promover a educação para e na cidadania;

II - a pesquisa, a análise e a aplicação dos resultados de investigações de interesse da área educacional;

III - a participação na gestão de processos educativos e na organização e funcionamento de sistemas e instituições de ensino. (BRASIL, 2006)

Tais diretrizes deixam evidente a complexidade do processo de formação do Curso que se coloca, atualmente, entre os de maior oferta na modalidade presencial e a distância. De acordo com dados do Censo da Educação Superior de 2016, o Curso de Pedagogia ocupa o terceiro lugar entre os dez cursos com maior número de estudantes, totalizando 513 mil matrículas (BRASIL, 2016). Por sua vez, de acordo com o Censo da Associação Brasileira de Educação a Distância (ABED, 2015), a área de Ciências 
Humanas encontra-se em segundo lugar em número de cursos regulamentados e totalmente a distância, com um total 324 cursos, dentre os quais, o curso de pedagogia (ABED, 2015, p. 43).

Em relação a todos os cursos de graduação observa-se que em 2016, 34.366 cursos na modalidade presencial e a distância foram ofertados em 2.407 instituições de educação superior no Brasil (Brasil, 2016). Embora se observa um crescimento de matrículas, a permanência tem se constituído em grave problema. Nesse sentido, não basta apenas o acesso, mas a permanência e a conclusão dos cursos.

Conforme Laham e Lemos (2016, p. 2), “a educação a distância tem crescido no Brasil com grande velocidade e objetivando suprir a necessidade de levar formação superior e especialização a uma parcela da população que, por diversos fatores, não teria condições de frequentar um curso presencial”.

No que se refere à evasão em cursos de $\mathrm{EaD}$, objeto do estudo, os obstáculos enfrentados pelas instituições ${ }^{3}$, tem se agravado o que motivou o interesse em analisar a evasão em um curso de Licenciatura em Pedagogia a distância.

\section{Procedimentos teórico-metodológicos}

Trata-se de uma pesquisa qualitativa e busca compreender por que e como fenômeno da evasão acontece a partir dos dados de uma instituição de ensino superior. Discute a influência as condições econômicas e as dificuldades de aprendizagem na permanência dos estudantes a partir do aporte teórico de Bourdieu (2000; 2003; 2010; 2014), e, ainda de Bourdieu; Passeron (2016), considerando os conceitos de habitus e de capital cultural.

Inicialmente, foram levantadas informações gerais sobre o curso de Licenciatura em Pedagogia a distância localizado da Região Sul, considerando o período compreendido entre 2005 a 2016, em relação à quantidade de alunos ingressantes, como também do número de alunos que não continuaram seus estudos e daqueles que obtiveram seu diploma. A partir desses dados, foi possível fazer um mapeamento da trajetória escolar desses estudantes e estimar as taxas de diplomação e evasão,

\footnotetext{
${ }^{3}$ De acordo com pesquisa realizada pela $\operatorname{ABED}(2015$, p. 48), 40\% das instituições que ofereceram cursos regulamentados totalmente a distância apresentaram uma evasão de $26 \%-50 \% ; 28 \%$ dos estabelecimentos apresentaram um percentual de desistência entre $11 \%-25 \% ; 16 \%$, entre $6 \%-10 \%$; e $9 \%$, entre $0 \%-5 \%$. Há, inclusive, $7 \%$ das instituições que ofereceram cursos da categoria citada que registraram uma taxa de evasão na faixa de $51 \%-75 \%$. Nenhum outro tipo de curso apresentou mais de $2 \%$ de instituições com esse nível de taxa de evasão.
} 
considerando-se o ano de ingresso. A base de dados do estudo é constituída pelas informações presentes no cadastro do sistema acadêmico da instituição foco de pesquisa e de um questionário aplicado a 14 (quatorze) professores/tutores ${ }^{4}$ do Curso.

Dentre os professores/tutores que participaram da pesquisa 13 (treze) são do sexo feminino e 1 (um) do sexo masculino, sendo a maioria com idade entre 30 a 40 anos. O tempo de trabalho na área da Educação a Distância como professor tutor varia de um mês a mais de 10 anos, sendo que a maioria atua no Curso entre dois a cinco anos, como podemos observar no gráfico a seguir.

O questionário aplicado é composto por 9 (nove) questões, dentre elas 5 (cinco) fechadas e 4 (abertas) abertas. As primeiras questões tiveram o objetivo de levantar dados para caracterizar o perfil dos participantes da pesquisa e na sequência questões relacionadas às percepções sobre a evasão no Curso.

Para este levantamento questionou-se se os mesmos já tinham recebido algum tipo de contato de alunos por e-mail, telefone ou em ambiente virtual indicando que iriam desistir do Curso de Pedagogia. E todos, sem exceção, se manifestaram afirmando que já receberam registros de alunos que pretendiam desistir do Curso.

Solicitou-se ainda no questionário que descrevessem algum caso em que o aluno informou que desistiria de seu Curso e que relatassem qual foi a orientação dada.

Nesse sentido algumas falas se destacam entre as quais a da participante T6:

Na maioria das vezes os alunos relatam que vão desistir do curso por causa do momento pessoal em que se encontram, problemas familiares; e outros porque não se adaptaram com a EAD, pensando que seria mais fácil, reclamam que é muita coisa para fazer e não dão conta. Como foi por tutoria o encaminhamento é apresentar a importância de estudar, de ter conhecimento e que nós estamos ali para ajudar e auxiliar nas dificuldades encontradas, fazemos um discurso de aumento da autoestima e várias situações os alunos voltam agradecendo. (T6)

Foi solicitado ainda que apontassem as maiores dificuldades encontrados pelo aluno que estuda Pedagogia a Distância, que citassem as causas da evasão e para finalizar deixamos uma pergunta aberta. Essas questões são analisadas ao longo do texto do artigo.

Para atingir os objetivos propostos inicialmente, se buscou levantar informações sobre o tema em estudo, delimitando assim um campo de trabalho e mapeando as

${ }^{4}$ Os participantes da pesquisa são todos contratados como professores do Curso, por isso a nomenclatura adotada na pesquisa Professor/tutor. 
condições de manifestação desse fenômeno. A partir deste levantamento foi realizada uma análise dos dados da pesquisa buscando compreender o fenômeno em estudo a partir de referencial sobre a temática, em especial, com o aporte teórico de Bourdieu.

\section{Acesso, permanência e evasão}

A história da educação superior no país evidencia um ensino elitizado, com um número de vagas muito limitado. Com a Lei de Diretrizes e Bases da Educação Nacional - LDBEn - Lei $n^{\circ}$ 9294/96, quando se incentivou a abertura de novas Instituições de Educação Superior (IES), ampliaram-se as vagas nos cursos de graduação, mas como ocorreu, principalmente em instituições privadas, a dificuldade de acesso permaneceu (BRASIL, 1996).

Segundo o Censo (2016), as IES que abriram após a década de 1990 confirmam essas suposições. Em 2003, existiam no Brasil 1752 instituições de educação superior e, em 2016, esse número aumentou para 2407 instituições. Destas, 12,3\% são públicas e $87,7 \%$ são particulares, caracterizando a educação superior no país como um ensino de elite e favorecendo tão somente alguns alunos sem condições econômicas mediante bolsas. Percebe-se, assim, que de cada quatro estudantes de graduação, três estudam em instituições privadas. Em relação à Educação a Distância $(\mathrm{EaD})$, vem ocorrendo também um aumento de matrículas, principalmente, após a publicação do Decreto 5.622, de 19 de dezembro de 2005, que regulamentou o artigo 80 da Lei de Diretrizes e Bases da Educação Nacional (LDBEN), Lei no 9394/96. Observa-se que o número de matrículas na modalidade a distância continua crescendo, atingindo quase 1,5 milhão em 2016, o que já representa uma participação de 18,6\% do total de matrículas da educação superior (BRASIL, 2016).

O aumento no número de matrículas e também de cursos criou a necessidade de maior atenção com a qualidade do ensino, principalmente na educação a distância, em que o ensino não se resume a bons professores frente às disciplinas. $\mathrm{Na} \mathrm{EaD}$, a qualidade também está atrelada à comunicação com os alunos, uma vez que professor, aluno e professor-tutor não compartilham do mesmo espaço físico e a comunicação é baseada nas tecnologias da informação, como indicado no Decreto n. 5.622/05, artigo $1^{\circ}$, que assim define a $\mathrm{EaD}$ : 
Para os fins deste Decreto, caracteriza-se a educação a distância como modalidade educacional na qual a mediação didático-pedagógica nos processos de ensino e aprendizagem ocorre com a utilização de meios e tecnologias de informação e comunicação, com estudantes e professores desenvolvendo atividades educativas em lugares ou tempos diversos. (BRASIL, 2005)

O incentivo ao aumento de vagas e a consequente ampliação do número de pessoas com educação superior constituem uma iniciativa importante, não obstante o aumento de ofertas de vagas, principalmente nas IES privadas, tenha sido mais amplo que o aumento do número de ingressantes, além dos índices de evasão, que são costumeiramente mais amplos nas IES privadas. A evasão é, certamente, um dos problemas que afligem as instituições de educação em geral, pois, Segundo Baggi e Lopes (2011),

[...] a evasão é um fenômeno social complexo, definido como interrupção no ciclo de estudos. É um problema que vem preocupando as instituições de ensino em geral, sejam públicas ou particulares, pois a saída de alunos provoca graves consequências sociais, acadêmicas e econômicas. (BAGGI; LOPES, 2011, p. 1)

Um dos fatores que dificulta a conclusão da educação superior pode estar situado na trajetória de escolaridade dos estudantes, que segundo Baggi e Lopes (2011, p. 5), esta é influenciada pelo capital cultural; a desigualdade social existente afeta diretamente aqueles estudantes de menor poder aquisitivo e é motivo de preocupação constante dos sistemas de ensino públicos e privados. Essa problemática já foi amplamente analisada por Bourdieu e Passeron (2014) no livro Os herdeiros, quando mostram como o sucesso na educação superior tem relação com a origem social dos estudantes.

Lê-se nas chances de acesso ao ensino superior o resultado de uma seleção que, ao longo de todo percurso escolar, exerce-se com um rigor muito desigual segundo a origem social dos sujeitos, na verdade, para as classes mais desfavorecidas, trata-se puramente $\mathrm{e}$ simplesmente de eliminação [...] (BORDIEU; PASSERON, 2014, p. 16)

Conforme Gisi e Gurgel (2016, p. 34) quando os estudantes que conseguem ingressar na educação superior não permanecem e não concluem com sucesso o curso escolhido, é preciso repensar a educação superior, suas políticas, a organização, a gestão e o processo pedagógico das instituições de educação superior. 
Em se tratando da $\mathrm{EaD}$, que em geral é mais acessível em termos financeiros pode ser muito atraente para aqueles estudantes com dificuldades de ordem econômica, mas esta modalidade educacional requer maior autonomia para a apreensão e construção do conhecimento, o que é muito mais difícil para quem não contou com um processo educacional e condições sociais para tal modalidade.

\section{As múltiplas causas da evasão}

Independente da modalidade, presencial ou a distância, os estudos sobre a evasão têm evidenciado múltiplas causas e muitas têm relação com a situação financeira dos estudantes e as dificuldades de aprendizagem. Furtado e Alves (2012), em suas pesquisas, analisaram os fatores determinantes da evasão universitária dos alunos da Universidade do Vale do Rio dos Sinos, com o objetivo de identificar quais as variáveis que possuíam maior importância na decisão deles em evadir ou não. Após a análise realizada, constataram que os motivos mais relevantes para explicar a evasão foram disciplinas canceladas, média nas disciplinas, percentual de disciplinas concluídas, município de residência, os custos de transportes e a dificuldade de acesso, evidenciando dificuldades de aprendizagem e financeiras.

Já Bardagi e Hutz (2012) realizaram uma pesquisa com o objetivo de verificar se a relação com colegas e professores teve alguma influência ou impactou na evasão universitária. O objetivo da pesquisa também foi o de compreender, a partir da visão de alunos universitários, os reais motivos do abandono do curso. Dentre os resultados da pesquisa realizada, os autores citam que a estrutura curricular, às vezes, não favorece o envolvimento dos alunos em atividades como monitoria, bolsas de pesquisa, estágios, participação em representações discentes, grupos de estudo, entre outras. Indicam, também, que as dificuldades nos vínculos e relacionamentos fragilizam não só a escolha, mas a própria percepção de si mesmo. "Ao não se envolverem com atividades acadêmicas, os estudantes demonstraram uma experiência de graduação empobrecida e tenderam a supervalorizar o contato com colegas e professores, suas fontes quase exclusivas de informação e apoio" (BARDAGI; HUTZ, 2012, p. 180).

Outro aspecto que chama a atenção nos resultados obtidos por esses autores é o fato de terem identificado, na fala dos alunos, a relevância do papel do professor universitário. Andriola, Andriola e Moura (2006) também ressaltaram a importância do professor nos seus estudos sobre a evasão na educação superior ao realizarem uma 
pesquisa sobre o fenômeno da evasão discente em cursos de graduação da Universidade Federal do Ceará (UFC), na perspectiva de docentes e de coordenadores. Como resultados, apresentaram que a maioria dos coordenadores $(87 \%)$ e dos docentes $(74 \%)$ entrevistados apresentaram opinião favorável ao resgate da função do professor orientador, no âmbito interno da instituição. Atrelados a essa função, citam “[...] ser imprescindível a preparação do corpo docente, a disponibilidade de tempo para a execução dessa atividade e a existência de recursos materiais adequados a tal” (p. 8).

Já para Baggi e Lopes (2011, p. 2), é importante também que se priorize a compreensão das questões de ordem acadêmica, como as expectativas do aluno em relação ao curso ou à instituição, que podem encorajá-lo ou desestimulá-lo a priorizar a conclusão do seu curso.

De acordo com Silva Filho et al (2007),

[...] as questões de ordem acadêmica, as expectativas do aluno em relação à sua formação e a própria integração do estudante com a instituição constituem, na maioria das vezes, os principais fatores que acabam por desestimular o estudante a priorizar o investimento de tempo ou financeiro, para conclusão do curso. (SILVA FILHO et al, 2007, p. 2)

Felicetti e Fossatti (2014) realizaram um mapeamento comparativo da evasão entre alunos de cursos de licenciatura que são bolsistas do Programa Universidade para Todos (ProUni) e alunos não bolsistas. Os autores mostraram que, embora o ProUni seja um programa que favorece a permanência do aluno na graduação em licenciatura, ele não dá conta das demandas necessárias para um maior índice de permanência.

Em relação, especificamente, à evasão em cursos de graduação a distância, cabe citar o estudo realizado por Santos et al (2008 p. 9), com base em pesquisa realizada por Xenos, Pierrakeas e Pintelas, da Open University da Inglaterra, na qual classificaram os fatores que afetam os níveis de evasão em curso a distância em três categorias: fatores relacionados às percepções do aluno e seu lócus de controle (interno e externo); fatores relativos ao curso e aos tutores; fatores relacionados a certas características dos estudantes, como idade, sexo, estado civil, número de filhos, tipo de trabalho ou profissão, entre outras. Os resultados do estudo mostraram que a maior parte das causas está relacionada a "causas extrínsecas", como a falta de tempo, problemas de saúde e não adequação ao modelo de $\mathrm{EaD}$. No que se refere às causas intrínsecas ao curso, que aparecem com menor frequência, foi salientado pelos estudantes a falta de acompanhamento do professor-tutor e falta de apoio/incentivo institucional. 
Outra pesquisa que podemos destacar é a de Laham e Lemes (2016) que percebem em pesquisa realizada com alunos evadidos, ativos e formados no curso a distância de Licenciatura em Pedagogia UAB-UFSCar, que dentre os estudantes evadidos a maioria apresentou o fator tempo como o motivo mais forte para a desistência do curso.

A evasão em cursos de EaD no Brasil apresenta-se como um dos obstáculos enfrentados pelas instituições. De acordo com pesquisa realizada pela ABED (2014, p. 78), das 109 instituições, 90 forneceram dados sobre evasão, obtendo-se as seguintes informações sobre as causas da evasão: “[...] falta de tempo para o estudo e participação nos cursos. Em seguida está a falta de adaptação à metodologia, apontado por 39 instituições, e, em terceiro lugar, o acúmulo de atividades de trabalho, apontado por 30 estabelecimentos como principal causa para evasão".

\section{O que revelam os dados da instituição}

A partir dos dados da pesquisa realizada com os estudantes pode-se representar o número de ingressantes e o número dos que abandonaram o curso no decorrer dos anos. Dos 101.935 estudantes que ingressaram no curso no período entre 2005 a 2016, ocorreu uma evasão de 41.043 alunos o que representa $41 \%$ dos estudantes. Destes, 30.071 alunos abandonaram o curso sem justificar, 487 transferiram-se para outra instituição e 10.845 alunos cancelaram sua matrícula apresentando uma justificativa o que representa $26,42 \%$.

Para esse estudo, foram considerados apenas os dados dos alunos que cancelaram sua matrícula e descreveram seus motivos no sistema acadêmico da Instituição. Pelo Gráfico 1, pode-se perceber que a quantidade de alunos que ingressaram no curso ao longo desses anos foi grande, porém, o número de desistentes também.

Gráfico 1: Quantidade de alunos ingressantes no curso (2005-2016) 


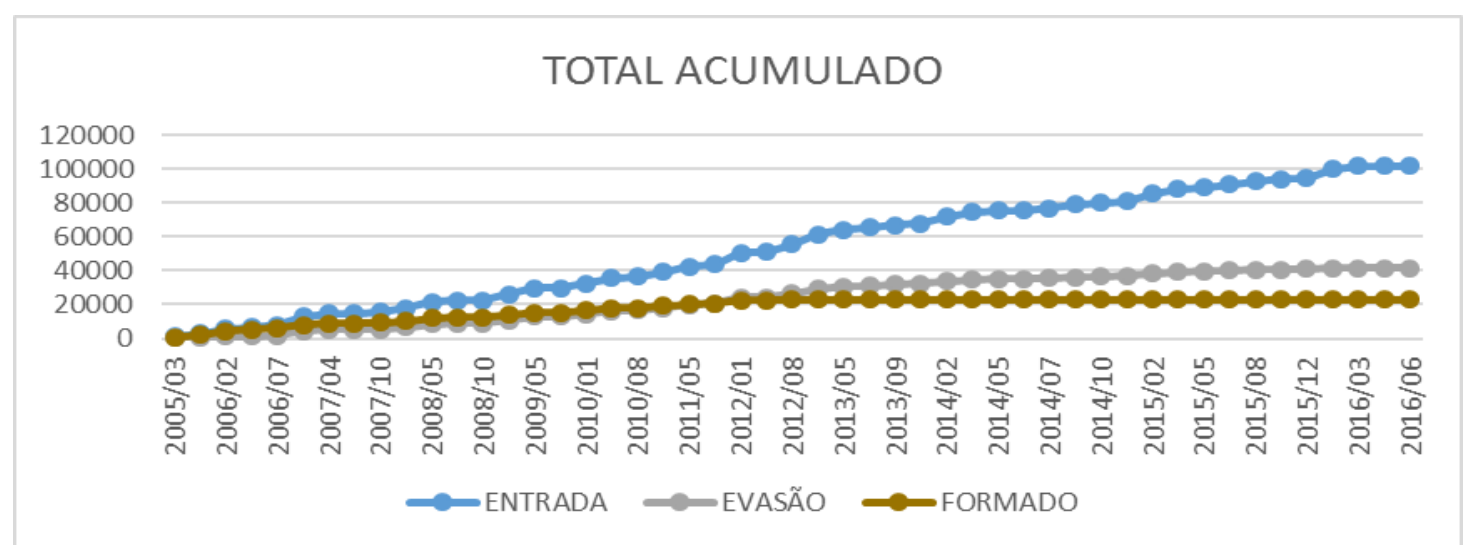

Fonte: Elaborado a partir dos dados da instituição pesquisada.

No Gráfico 2, observa-se o percentual dos alunos concluintes, assim como o percentual de alunos que abandonaram o curso, desde sua primeira turma 2005 - 2016. Se considerado o período de 2007 a 2012, o percentual de evasão ultrapassou os 50\% dos alunos ingressantes no curso.

Gráfico 2: Percentual de concluintes e de evasão no curso.

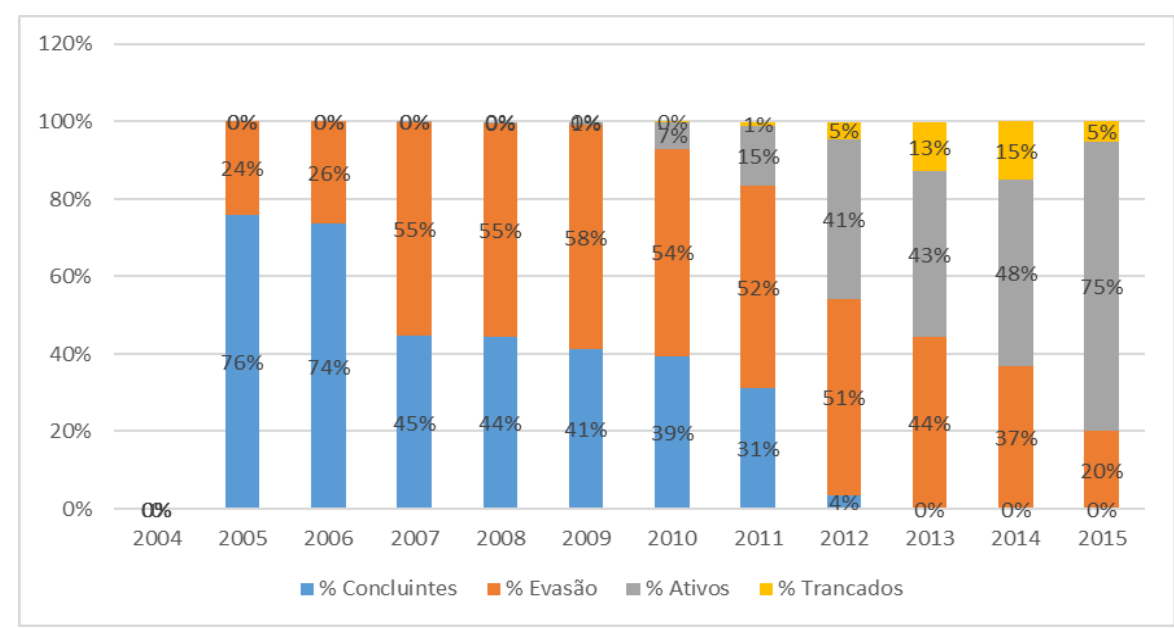

Fonte: Elaborado a partir dos dados da instituição pesquisada

Os motivos apresentados pelos estudantes sobre a evasão foram agrupados em quatro categorias: problemas financeiros, trabalho, questões acadêmicas e problemas pessoais. Em cada uma das categorias são apresentadas justificativas de estudantes.

\section{Problemas Financeiros}

Como já apontado por Silva Filho et al (2007), na sua pesquisa sobre evasão as instituições públicas e privadas dão como principal razão da evasão a falta de recursos financeiros para o estudante prosseguir nos estudos e que esse é também o motivo 
alegado pelos alunos quando perguntados sobre a principal razão da evasão, o que pode ser compreendido na fala dos participantes:

Adorei o curso, materiais muito bons, espero dar continuidade ao curso ainda, mas devido a problemas financeiros infelizmente vou ter que cancelar, assim poder dar um aproveitamento melhor as aulas voltarei. (A4)

Estou cancelando por não ter conseguido a bolsa de estudos neste semestre, e estou com dificuldades financeiras. (A28)

O que se percebe é que os motivos apresentados pelos alunos, como justificativas, revelam na maioria das vezes questões relacionadas à dificuldade financeira e considerando as pesquisas realizadas por Bourdieu (2016), sabe-se que justamente aqueles estudantes que tem menores condições econômicas também tem carência de capital cultural ${ }^{5}$ o que, por sua vez, tem relação com o habitus $^{6}$. Pensar no habitus, implica pensar a relação entre indivíduo e sociedade, implica afirmar que o individual, o pessoal e o subjetivo são simultaneamente sociais e coletivamente orquestrados.

A permanência na Educação Superior pressupõe condições permanentes, em especial capital cultural, que é adquirido ao longo da trajetória de vida e escolar e que não se obtém de um momento para o outro. Sobre essa questão é pertinente retomar os estudos de Bourdieu (2003, p. 28) sobre o capital cultural incorporado em razão das oportunidades sociais que possuem os alunos. Ao referir-se ao capital cultural incorporado, aponta o autor que essa incorporação pressupõe assimilação, é pessoal, leva tempo, é um trabalho do sujeito sobre si mesmo. O capital cultural é, assim, um ter que se tornou ser, é parte integrante da pessoa, é um habitus.

Na pesquisa realizada com os professore/tutores do Curso, os mesmos destacam em primeiro lugar dificuldades nos estudos, o que evidencia o peso do capital cultural

${ }^{5}$ Bourdieu (1987, p. 33) considera: o capital cultural, que compreende o conhecimento, as habilidades, as informações etc., correspondente ao conjunto de qualificações intelectuais produzidas e transmitidas pela família, e pelas instituições escolares, sob três formas: o estado incorporado, como disposição durável do corpo (por exemplo, a forma de se apresentar em público); o estado objetivo, como a posse de bens culturais (por exemplo, a posse de obras de arte); estado institucionalizado, sancionado pelas instituições, como os títulos acadêmicos; o capital social, correspondente ao conjunto de acessos sociais, que compreende o relacionamento e a rede de contatos; o capital simbólico, correspondente ao conjunto de rituais de reconhecimento social, e que compreende o prestígio, a honra etc. O capital simbólico é uma síntese dos demais (cultural, econômico e social). (THIRY-CHRQUES, 2006, p. 15).

${ }^{6}$ O habitus é uma subjetividade socializada (BORDIEU, 2010, p. 101). Dessa forma, deve ser visto como um conjunto de esquemas de percepção, apropriação e ação que é experimentado e posto em prática, tendo em vista que as conjunturas de um campo o estimulam. 
no sucesso dos estudantes em sua trajetória de escolaridade. E, descreveram casos em que o aluno informou que desistiria de seu Curso conforme o relato do tutor:

A aluna queria desistir, pois estava com muita dificuldade em elaborar seu relatório de estágio de Educação Infantil, já era a terceira ou quarta vez que estava em regime tutorial na referida disciplina. Ela enviou via link de tutoria suas dúvidas e a orientei em cada tópico do relatório, apontando o que precisaria ser melhorado, pois a mesma alegava não entender as correções feitas no trabalho pela equipe de correção. A aluna se acalmou com o tempo e seu trabalho teve uma melhora significativa depois das orientações. (T1)

Percebemos no relato, as dificuldades que o aluno apresenta em realizar as atividades e em entender o que se estava pedindo nas correções de seu trabalho evidenciando falta de autonomia do aluno e a defasagem no seu conhecimento.

\section{Trabalho}

As minhas prioridades profissionais atuais me demandam um tempo no qual é necessário dispor de um tempo que interfere diretamente ao tempo que precisaria. (A15)

Essa questão também foi apontada pelos professores/tutores como podemos observar no relato, quando foi pedido para que descrevessem algum caso em que o aluno informou que desistiria de seu Curso:

Dificuldade em cumprir as disciplinas pendentes no tempo de curso disponível. Orientação: analisar com calma prazo e quantidade de disciplinas, se atentar ao período de solicitação e organizar-se para cumprir o cronograma. (T5)

\section{Questões Acadêmicos}

Percebemos aqui a dificuldade que o aluno tem com as tecnologias digitais. $\mathrm{O}$ uso das tecnologias ainda se apresenta como um desafio na formação dos alunos, desta forma a ação da tutoria é um elemento essencial, sendo uma das determinantes do sucesso do curso.

Encontrei muita dificuldade no portal para estudar e fazer os trabalhos. (A36)

Estou pedindo o cancelamento por dificuldades de acesso no sistema da universidade, pois moro no interior. (A40)

Estou me desligando pois não consegui acompanhar as datas das provas. (A41) 


\title{
Problemas Pessoais
}

Nesta categoria estão incluídos problemas relacionados à saúde, mudança de cidade e não identificação com o curso

Não cursei nem um mês pois tive que ir embora da cidade e para onde fui não tinha acesso à internet, se possível desconsidere meus débitos. (A52)

Embora problemas pessoais (de saúde, psicológicos e em casa) estejam fora do controle da IES, essa pode ofertar serviços de orientação psicológica e de saúde aos alunos. Tendo em vista o grande impacto dessa dimensão na evasão, os alunos podem vir a permanecer se tiverem a IES como ponto de apoio.

Em relação às dificuldades apresentadas para acompanhar os estudos, fica muito clara a influência da insuficiência de capital cultural na decisão de abandonar os estudos uma vez que, os estudantes possuem qualificações produzidas e transmitidas pela família, e pelas instituições escolares, que tem posse de bens culturais tem na sua maioria, conforme Bourdieu (2014) mais chances de alcançar o sucesso nos estudos.

Na pesquisa realizada com tutores dos Curso a "Falta de informação sobre o curso ou atividades pedagógicas" foi citada por quatro professores/tutores como a maior causa da evasão.

Destacam-se os seguintes relatos:

\begin{abstract}
Alunos comentam que estão perdidos, especialmente os calouros e por isso, desistem ou realizam atividades reclamando. Há uma busca por conclusão fácil do curso. (T3)

$\mathrm{O}$ aluno estava insatisfeito com o curso, sentindo-se desrespeitado nos seus direitos. Conversando com o aluno, pude identificar que sua insatisfação se devia mais ao não conhecimento dos prazos de realização das atividades virtuais. Mostrei ao aluno que um pouco de organização, como a leitura dos manuais e um controle das datas das atividades principais do curso, resolveria boa parte dos problemas. (T5)
\end{abstract}

Para Silva (2013, p. 12), “[...] é possível tomar medidas de caráter pedagógico e de atendimento ao aluno de forma a sanar suas dificuldades no acompanhamento do curso, que culmina na reprovação, ou ainda com relação ao pagamento das mensalidades do curso".

A pesquisa realizada com os professores/tutores também mostra que a desinformação e/ou informações distorcidas sobre o Curso contribui para a evasão, o aluno precisa estar constantemente informado sobre como é o funcionamento do seu 
Curso, como se dá o processo de ensino e aprendizagem na modalidade a distância, como é o sistema de avaliação, as atividades a serem desenvolvidas. E tudo isso deve ser muito bem explicado desde o início, para que o estudante consiga acompanhar e também desenvolver a sua autonomia. Podemos observar nos relatos abaixo, algumas dificuldades encontradas pelos alunos devido à falta de informação:

Desmotivação, curso não correspondia às expectativas iniciais [...]. A primeira atitude foi a de OUVIR e ACOLHER. Uma das alunas retornou e refez as disciplinas no sistema [...]. Para uma aluna, junto com a coordenação, foi sugerido atendimento psicológico e avaliação com neuro, pois estava encontrando dificuldades na escrita, problemas emocionais e por comentar conosco sobre sua dislexia (mas não tinha laudo); além disso, a aluna foi orientada sobre as estratégias de leitura para disléxicos. (T8)

Além da informação, Dose (2017, p. 3) salienta que os feedbacks durante o processo de ensino-aprendizagem, nos retornos das atividades propostas como os fóruns conceituais, fórum de dúvidas, e-mails, blogs e diversas outras ferramentas são relevantes para a construção da autonomia desse aluno e para a sua aprendizagem na educação a distância.

Muito se engana quem acredita que estudar a distância é mais fácil. Relatos dos professores/tutores confirmam a dificuldade que os alunos apresentam em acompanhar esta modalidade:

A Aluna queria trancar o curso de Pedagogia por não estar conseguindo acompanhar o ritmo dos estudos. Sentamos para conversar e a orientei sobre os procedimentos da modalidade, além de me disponibilizar para qualquer dúvida que tivesse. Esta aluna está concluindo seu curso. (T10)

O tema evasão é bem delicado, pois depende do contexto de vida de cada estudante. Mas o que mais se destaca na $\mathrm{EaD}$ é a dificuldade do aluno em organizar seus estudos e a alegação de falta de suporte, e é claro que temos que instigar a autonomia dos alunos, mas em um primeiro momento precisamos mostrar que eles têm nosso apoio sempre que precisarem e irmos mostrando o caminho para que eles possam desenvolver a autonomia que é indispensável nesta modalidade de ensino. (T2)

Aluno relata que não consegue estudar por meio de artigos ou livros, que tem muitas atividades para fazer, que achava que seria mais fácil estudar a distância e além disso, tem dificuldades para usar o sistema operacional. Geralmente, passo algumas dicas em formato de check list de atividades para orientar o aluno com intuito de nortear o estudo inicial, incentivo o aluno a postar novas perguntas sempre que precisar e destaco o quanto é importante persistir frente as dificuldades iniciais até que se aproprie do sistema e dos conhecimentos básicos iniciais. (T14) 
Para os professores/tutores as maiores dificuldades encontrados pelo aluno que estuda Pedagogia a Distância são:

Compreensão dos comunicados, muitos alunos têm dificuldade na interpretação e acabam se equivocando no entendimento de informações importantes; - Outro fator é que muitos têm necessidade de interação, querem trocar ideias com outros alunos e tutores e muitas vezes não conseguem respaldo do polo presencial. Outra dificuldade é o aluno organizar sua rotina de estudos de maneira eficiente, não deixar atividades acumularem. Muitos não conseguem ter essa autonomia nos estudos. (T5)

Muitas vezes, o fracasso escolar é produzido por um desencontro entre as formas de pensamento e expressão usados pela educação, pela escola e aquelas que fazem parte do habitus dos alunos que não tiverem condições sociais e econômicas para uma trajetória escolar de sucesso. A própria noção de fracasso escolar remete a um problema de mobilidade social.

Segundo Bourdieu e Passeron (2014):

Crer que são dadas a todos oportunidades iguais de acesso ao ensino mais elevado e a cultura mais alta quando se garantem os mesmos meios econômicos aos que tem os 'dons' indispensáveis é ficar no meio do caminho na análise dos obstáculos e ignorar que as aptidões medidas pelo critério escolar têm, mais dos 'dons' naturais [...], uma maior ou menor afinidade entre os hábitos culturais de uma classe e as exigências do sistema de ensino ou os critérios que para ele definem o sucesso. (BORDIEU e PASSERON, 2014, p. 39)

Conforme Gisi e Ens (2015, p. 183) embora existam iniciativas governamentais que contemplam a ampliação de vagas nas instituições de Educação Superior, o país ainda se encontra distante de possuir um sistema de Educação Superior democratizado.

Expandir o acesso da Educação Superior é um grande desafio para aumentar a escolaridade média da população. Promover a interiorização das instituições, aumentar o número de vagas e criar mecanismos de inclusão de populações marginalizadas são algumas medidas que devem ser desenvolvidas para que a meta seja atingida.

Na educação superior, a desigualdade inicial das diversas camadas sociais diante da escola aparece, primeiramente, no fato de serem desigualmente representadas (Bourdieu e Passeron, 2014, p. 16). Segundo Gisi (2006, p. 108), quando os alunos chegam na escola em situação de desigualdade, reconhecer esta desigualdade deve ser o ponto de partida para o repensar do projeto pedagógico de um curso. 


\section{Considerações finais}

O estudo indica que as causas da evasão em um curso de Pedagogia a distância têm relação, em especial, com dificuldades financeiras, dificuldades de aprendizagem e/ou com a modalidade da educação a distância, evidenciando que são estas as dificuldades que mais impactam os estudantes. Tal constatação demonstra que somente ampliar vagas em instituições privadas não poderá atender o preconizado pelo Plano Nacional de Educação de ampliar a taxa líquida de $33 \%$ e à taxa bruta de $50 \%$ de matrículas na educação superior (BRASIL, 2014). Até mesmo a ampliação de vagas nas instituições públicas requer apoio financeiro para alimentação, transporte, moradia e compra de material de estudos. Assim, mesmo o aumento de bolsas que liberam o pagamento de mensalidades pode não ser suficiente.

Não se pode ignorar, no entanto, as dificuldades dos estudantes em acompanhar as aulas relacionadas com a modalidade $\mathrm{EaD}$, o que requer atenção especial em relação à metodologia, mas isto também pode ser resultado da sua trajetória escolar, pois, segundo os professores/tutores envolvidos na pesquisa, as maiores dificuldades são a defasagem na educação básica, a pouca autonomia para pesquisar e falta de tempo para estudar. Conforme os professores/tutores, o aluno da $\mathrm{EaD}$ deve ter muita disciplina para adequar-se ao ritmo e a dinâmica da EaD. No geral, percebe-se que os alunos da $\mathrm{EaD}$ pensam que é mais fácil o estudo a distância, mas acabam tendo dificuldades relacionadas a falta de organização e acompanhamento das atividades.

A crescente importância do diploma escolar, enquanto credencial e certificado de competências técnicas e sociais ou simbólicas, dando acesso ao trabalho e, consequentemente, determinando as remunerações econômicas dos indivíduos, mobiliza os estudantes para a educação superior, no entanto poucos conseguem concluir esta etapa de ensino.

Independente da modalidade, educação presencial ou educação a distância, a evasão tem sido frequente. Na medida que o estudo confirma que a ocorrência da evasão tem relação principalmente, com dificuldades financeiras e de aprendizagem, aquelas que decorrem da situação familiar e da trajetória escolar dos estudantes, se faz necessário um esforço conjunto de valorização da educação no país, da melhoria das condições sociais e econômicas da população e do esforço das instituições de educação a distância em oferecer as condições para a aprendizagem. 


\section{REFERÊNCIAS}

ASSOCIAÇÃO BRASILEIRA DE EDUCAÇÃO A DISTÂNCIA. Censo/2014 EaD Relatório Analítico da aprendizagem a distância no Brasil. 2016. Disponível em: <http://www.abed.org.br/censoead2014/CensoEAD2014_portugues.pdf>. Acesso em: 04 maio 2018.

ANDRIOLA, W.; ANDRIOLA, C. G.; MOURA, C. P. Opiniões de docentes e de coordenadores acerca do fenômeno da evasão discente dos cursos de graduação da Universidade Federal do Ceará (UFC). Ensaio: Aval. Pol. Públ. Educ., v. 14, n. 52, Rio de Janeiro, jul./set. 2006.

BAGGI, C. A. S.; LOPES, D. A. Evasão e avaliação institucional no ensino superior: uma discussão bibliográfica. Avaliação, v. 16, n. 2, Sorocaba, jul., 2011.

BARDAGI, M. P.; HUTZ, C. S. Rotina Acadêmica e Relação com Colegas e Professores: Impacto na Evasão Universitária. PSICO, Porto Alegre, PUCRS, v. 43, n. 2, p. 174-184, abr.jun., 2012.

BOURDIEU, P. O campo econômico. Campinas/SP: Papirus. 2000.

BOURDIEU, P. Economia das trocas simbólicas. São Paulo: Perspectiva. 2003.

BOURDIEU, P. O poder simbólico. 13 ed. Rio de Janeiro: Bertrand Brasil. 2010.

BOURDIEU, P.; PASSERON, J. Os herdeiros: os estudantes e a cultura. Florianópolis: Ed. da UFSC. 2014.

BOURDIEU, P.; PASSERON, J. A reprodução. Petrópolis, Vozes, 2016.

BRASIL Censo EAD Brasil 2016. Disponível em:

<http://abed.org.br/censoead2016/Censo_EAD_2016_portugues.pdf〉. Acesso em: 10 maio 2018.

BRASIL. Decreto n $\mathbf{n}^{\mathbf{5}} \mathbf{5 . 6 2 2}$, de 19 de dezembro de 2005. Regulamenta o art. 80 da Lei n. 9.394, de 20 de dezembro de 1996, que estabelece as diretrizes e bases da educação nacional, 2005. Disponível em: <http://www.planalto.gov.br/ccivil_03/_ato20042006/2005/decreto/d5622.htm>. Acesso em: 10 maio 2018.

CONSELHO NACIONAL DE EDUCAÇÃO. Institui Diretrizes Curriculares Nacionais para o Curso de Graduação em Pedagogia, licenciatura. Resolução CNE/CP no 1, de 15 de maio de 2006. Disponível em:

<http://portal.mec.gov.br/cne/arquivos/pdf/rcp01_06.pdf>. Acesso em: 10 maio 2018.

DOSE, E. M. C. A importância do feedback na educação a distância. Revista on line de Política e Gestão Educacional, v.21, n.3, p. 1565-1571, set./dez., 2017.

FELICETTI, V. L.; FOSSATTI, P (2016). Alunos ProUni e não ProUni nos cursos de licenciatura: evasão em foco. Educar em Revista, n. 51, jan./mar., 2014. 
FURTADO, V. V.; ALVES, T. W (2016). Fatores determinantes da evasão universitária: Uma análise com alunos da UNISINOS. Contextus, v. 10, p. 115 -129, 2012.

GISI, M. L. A educação superior no Brasil e o caráter de desigualdade do acesso e da permanência. Revista Diálogo Educacional, 2006.

GISI, M. L.; ENS, R. T. Políticas de acesso à Educação Superior: por que avaliar? Revista Diálogo Educacional, 2015.

GISI, M. L; PEROGINI, D. G. As políticas de acesso e permanência na educação superior: a busca da igualdade de resultados. Revista on line de Política e Gestão Educacional, v. 20, n. 1, jan. abril, 2016.

LAHAM, S. A. D.; LEMES, S. S. Um estudo sobre as possíveis causas de evasão em curso de licenciatura em pedagogia a distância. Revista on line de Política e Gestão Educacional, v.20, n.03, p. 405-431, 2016

MINISTÉRIO DA EDUCAÇÃO. INEP - Instituto Nacional de Estudos e Pesquisas Educacionais Anísio Teixeira. Censo da Educação Superior 2016. Brasil, 2017. Disponível em: <http://www.inep.gov.br>. Acesso em: 10 maio 2018.

Ministério da Educação. Plano Nacional de Educação. Lei 13.005/2014b. Brasil, 2014. Disponível em: <http://www.mec.gov.br>. Acesso em: 10 maio 2018.

SANTOS, E. M. et al. Evasão na educação a distância: identificando causas e propondo estratégias de prevenção. 2016. Disponível em:

<http://www.abed.org.br/congresso2008/tc/552008112738pm.pdf>. Acesso em: 10 maio 2018.

SILVA FILHO, R. L. L. et al. A evasão no ensino superior brasileiro. Cad. Pesqui., v. 37, n. 132, São Paulo, set./dez., 2007.

SILVA, F. I. C. et al. Evasão escolar no curso de educação física da Universidade Federal do Piauí. Avaliação, v. 17, n. 2, jul., 2012.

SILVA, G. P. da. Análise de evasão no ensino superior: uma proposta de diagnóstico de seus determinantes. Avaliaçã, v. 18, n. 2, jul., 2013.

THIRY-CHERQUES, H. R. Pierre Bourdieu: a teoria na prática. Rev. Adm. Pública, v. 40, n. 1, Rio de Janeiro, jan./fev., 2006.

TONTINIL, G.; WALTERLL, S. A. Pode-se identificar a propensão e reduzir a evasão de alunos? Ações estratégicas e resultados táticos para instituições de ensino superior. Avaliação, v. 19, n. 1, mar., 2014. 


\section{Como referenciar este artigo}

CORDEIRO, Gisele do Rocio.; GISI, Maria Lourdes. A evasão em curso de pedagogia a distância: um olhar a partir dos tutores. Revista on line de Política e Gestão Educacional, Araraquara, v. 22, n. 2, p. 627-645, maio/ago., 2018. ISSN: 1519-9029. DOI: 10.22633/rpge.v22.n2.maio/ago.2018.11229

Submetido em: 22/03/2018

Aprovado em: 30/04/2018 